\section{Akute Cholezystitis}

VON H. S. FÜEßL

Eine 42-jährige übergewichtige Frau wird von ihrem Mann am Samstagmorgen in die Nothilfe gebracht. Sie schwitzt stark, geht nach rechts gekrümmt und hält sich den Bauch. Am Tag zuvor hatte sie nach einer fettreichen Mahlzeit zunächst leichte, dann immer heftiger werdende Schmerzen im rechten Oberbauch empfunden. Der Schmerzverlauf war anfangs kolikartig mit einer Dauer von ca. 10-15 Minuten. Zusätzlich besteht seitdem eine anhaltende Übelkeit, die mehrfach von Erbrechen begleitet war. Im Laufe der Nacht war der kolikartige Schmerz in einen weniger heftigen Dauerschmerz übergegangen.

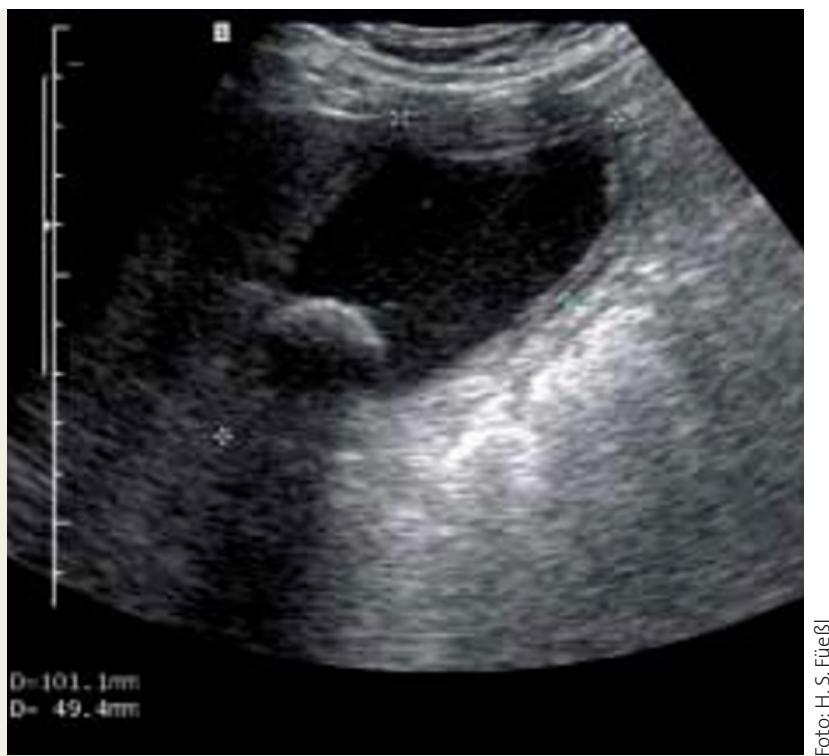

Sonografisches Bild der akuten Cholezystitis mit Solitärkonkrement.

\section{Sofortdiagnostik}

Die Anamnese ist typisch für eine initiale Gallensteinkolik:

- Die Frau fühlt sich heiß an, rektal werden $38,7^{\circ} \mathrm{C}$ gemessen.

- Im rechten Oberbauch besteht ein heftiger reproduzier-

barer Druckschmerz, der bei tiefer Inspiration besonders

stark auslösbar ist (Murphy-Zeichen).

- Er geht mit einer leichten Abwehrspannung einher.

- Die Peristaltik ist träge, die Zunge trocken.

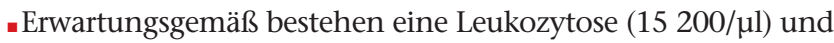
ein erhöhtes CRP (28,6 mg/l), die Transaminasen, alkalische Phosphatase, Lipase und Bilirubin liegen im Normbereich.

Die Oberbauchsonografie zeigt eine $10 \times 5 \mathrm{~cm}$ große Gallenblase mit einem Solitärkonkrement im Infundibulum und eine über $3 \mathrm{~mm}$ verdickte Gallenblasenwand mit deutlich erkennbarer typischer Dreischichtung durch das entzündliche Ödem. Die sonografisch gezielte Einfingerpalpation ist sehr schmerzhaft. Damit ist die Diagnose ausreichend gesichert.

\section{Sofortmaßnahmen}

Für den Hausarzt empfiehlt sich zunächst nur das Anlegen einer Infusion, eine i.v. Analgetika- bzw. Spasmolytika-Therapie mit N-Butylscopolamin und/oder Pentazocin sowie die Gabe von Antibiotika (Amoxicillin kombiniert mit Metronidazol).

\section{Endgültige Therapie/mögliche Komplikationen}

Die konservative Therapie der akuten Cholezystitis ist möglich. Es empfiehlt sich jedoch nach neueren Erkenntnissen eine frühe Operation (heute i. d. R. laparoskopisch). Die Konversionsraten hin zur offenen Operation, die Komplikationsrate und die Dauer des Krankenhausaufenthalts sind umso niedriger bzw. kürzer, je früher operiert wird.

Nach konservativer Therapie kommt es bei über einem Drittel zu Komplikationen oder Notaufnahmen wegen biliärer Schmerzen, bei 30\% wird im weiteren Verlauf doch eine Cholezystektomie erforderlich. Es besteht die Gefahr eines Rezidivs.
Alternativ zur Cholezystektomie kann bei älteren Patienten (> 65 Jahre) oder erhöhtem OP-Risiko eine perkutane Drainage der Gallenblase (Cholezystostomie) erwogen werden. Kann der Patient nicht frühelektiv (innerhalb der ersten 1 bis 5 Tage) operiert werden (zu späte Diagnosestellung, andere medizinische Gründe), sollte die Cholezystektomie im Intervall erst nach sechs Wochen erfolgen. Bei gedeckter oder freier Gallenblasenperforation besteht eine sofortige OP-Indikation.

Bei 10-30\% der Patienten mit akuter Cholezystitis kommt es zu schweren Komplikationen wie Gallenblasengangrän, -empyem oder -perforation. Eine Wandgangrän kann innerhalb weniger Stunden nach Beginn der Symptomatik auftreten. Daher sollte ein Patient mit Cholezystitis zur Beobachtung in die Klinik eingewiesen werden.

\section{Woran noch denken, was noch tun?}

Ohne Ergebnisse der apparativen Diagnostik umfasst die Differenzialdiagnose des rechtsseitigen Oberbauchschmerzes ein weites Feld:

- Gastroduodenalulkus

- Pankreatitis

- Appendizitis

- Pyelonephritis

- Pleuritis,

- Stauungsleber

- Myokardinfarkt.

Hierzu müssen evtl. einschlägige Untersuchungen erfolgen. In der Regel sind die sonomorphologischen Kriterien der akuten Cholezystitis aber so eindeutig, dass nicht invasiv eine sichere Diagnose gestellt werden kann.

\section{Anschrift des Verfassers:}

Prof. Dr. med. H. S. FüeßI, Leiter Somatischer Querschnittsbereich, Isar-Amper-Klinikum, Klinikum München-Ost,

Ringstr. 33a, D-85540 Haar, E-Mail: Hermann.Fueessl@iak-kmo.de 